\title{
Introduction to MERJ special issue, "Theoretical foundations of engagement in mathematics: empirical studies from the field"
}

\author{
${\text { Colin } \text { Carmichael }^{1} \text { (D) - Rosemary Callingham }}^{2}$. \\ Judy Anderson ${ }^{3}$
}

Received: 4 May 2017 / Accepted: 5 May 2017 /

Published online: 17 May 2017

(C) Mathematics Education Research Group of Australasia, Inc. 2017

Established theoretical frameworks have much to offer research on the practice of teaching and learning in mathematics. For example, they allow researchers to make sense of empirical findings. The purpose of this special issue is to present a number of theoretical frameworks related to engagement in mathematics and illustrate how these are used in empirical studies. Engagement in mathematics by school students has been a burgeoning area of inquiry, referring to cognitive, affective and behavioural dimensions (Fredricks et al. 2004), and associated contextual influences. Theoretical approaches to engagement have typically employed "inside-out" (within-person emphases) or "outside-in" (system/context) frameworks, and both are represented in this collection. Although all studies reported in this special issue focus on engagement in mathematics, the researchers have taken a variety of approaches to the topic, both theoretically and methodologically, providing a snapshot of contemporary mathematics education research.

Rather than write a "traditional" editorial to this special issue, the editors have chosen simply to introduce the issue, with the first paper by Helen Watt and Merrilyn Goos providing the topic overview and theoretical perspectives, and linking these to the

Colin Carmichael

ccarmichael@csu.edu.au

Rosemary Callingham

rosemary.callingham@utas.edu.au

Judy Anderson

judy.anderson@sydney.edu.au

1 Charles Sturt University, Albury, Australia

2 University of Tasmania, Hobart, Australia

3 University of Sydney, Sydney, Australia 
six contributed papers. The final paper, by Rudolf Sträßer, provides an international perspective and summary, with suggestions for future work.

Taken as a collection, there is much for mathematics education researchers to reflect on from this group of papers. They illustrate how even a single topic, engagement in mathematics, can be viewed through a variety of theoretical lenses, leading to studies taking very diverse perspectives. For example, Lazarides and Rubach interpret student responses to a survey through the lens of achievement goal theory (Dweck and Elliott 1983); Geiger and colleagues interpret a case study involving a group of secondary mathematics teachers using Valsiner's zone theory (Valsiner 1997); and, Durksen and colleagues analyse teacher interview data using a theoretical framework developed and integrated from a number of motivational theories. This diversity of theoretical perspectives is an acknowledged feature of research in our field (Bikner-Ahsbahs and Prediger 2006), arguably a consequence of the awkward relationship between its two constituent terms (Brown and Walshaw 2012). Sririman and English (2010) considered the challenge of providing an integrated theory of mathematics education and concluded that, at this point in time, this goal was unattainable. Interestingly in this special issue, Sträßer suggests a complex model in his commentary that might hold some promise towards unifying the field. Even this model, however, appears to miss the intricacy of systems and the political sphere of influence.

Where then should mathematics education research be heading? Is an integrated model worth pursuing or is there a richness in the variety of theories and approaches used in the field? There is considerable room for debate within mathematics education itself, and with those outside the field including practitioners and policy makers. MERGA as an organisation seems well placed to encourage discussion, nationally and internationally through its networks.

We hope that this special issue of the Mathematics Education Research Journal will promote discussion that goes beyond the immediate topic of engagement in mathematics.

\section{References}

Bikner-Ahsbahs, A., \& Prediger, A. (2006). Diversity of theories in mathematics education: how can we deal with it? ZDM, 38(1), 52-56.

Brown, T., \& Walshaw, M. (2012). Mathematics education and contemporary theory: guest editorial. Educational Studies in Mathematics, 80, 1-8.

Dweck, C. S., \& Elliott, S. (1983). Achievement motivation. In P. Mussen (Ed.), Handbook of child psychology: socialization, personality, and social development (Vol. 4, pp. 643-691). NY: Wiley.

Fredricks, J. A., Blumenfeld, P. C., \& Paris, A. H. (2004). School engagement: potential of the concept, state of the evidence. Review of Educational Research, 74(1), 59-109.

Sririman, B., \& English, L. (2010). Surveying theories and philosophies of mathematics education. In B. Sririman \& L. English (Eds.), Theories of mathematics education. Seeking new frontiers. Springer: Heidelberg.

Valsiner, J. (1997). Culture and the development of children's action: a theory of human development (2nd ed.). New York: Wiley. 